\title{
I Comunidades acuáticas de la laguna Aricota de Candarave
}

\section{Aquatic communities of the Aricota Lake, Candarave province}

\author{
,** Paola Franco Vásquez \\ Pablo Franco León \\ Liduvina Sulca Quispe \\ ${ }^{3}$ Eduardo Oyague
}

\author{
ORCID: 0000-0002-7585-2174 \\ ORCID: 0000-0002-6367-3515 \\ ORCID: 0000-0003-2573-8426 \\ ORCID: 0000-0003-3376-021X
}

\section{RESUMEN}

La laguna Aricota se ha mantenido "biológicamente" estable en los últimos años, a pesar de la extracción de agua por parte de las centrales hidroeléctricas (Aricota I y II) y la disminución del cauce por parte de sus afluentes (ríos Callazas y Salado). El objetivo del trabajo tuvo como propósito la identificación de las diferentes comunidades acuáticas (fitoplancton, perifiton, zooplancton, macroinvertebrados bentónicos y peces). El estudio se realizó durante cinco meses en 5 estaciones de muestreo, a fines de 2017 e inicios del 2018, a lo largo de la zona litoral y pelágica de la laguna. En los resultados, el fitoplancton estuvo representado por 52 morfoespecies distribuidas en: 6 Phyllum, 26 ordenes y 31 familias; el perifiton, con 56 morfoespecies distribuidas en: 8 Phyllum, 25 ordenes y 34 familias; el zooplancton, con 13 morfoespecies distribuidas en: 6 Phyllum, 8 ordenes y 11 familias; los macroinvertebrados estuvieron representados por 24 especies distribuidas en: 5 Phyllum, 9 ordenes y 16 familias; y la ictiofauna estuvo representada por Oncorhynchus mykiss y Trichomycterus sp. Los parámetros físico químicos presentaron valores promedio: la temperatura en la zona litoral de la laguna Aricota (HBO1, $\mathrm{HBO} 2, \mathrm{HBO} 3$ y $\mathrm{HBO} 4$ ) fue de $18.0-18.2{ }^{\circ} \mathrm{C}$, mientras que en la zona pelágica (HBO5) fue de $17.9-18.2{ }^{\circ} \mathrm{C}$; en el caso del oxígeno disuelto, la variación en la zona litoral fue de 7.14-7.24 mg/L y en la zona pelágica fue de 7.21-7.24 mg/L; para la conductividad eléctrica, la variación en la zona litoral fue de 1960-2031 $\mu \mathrm{S} / \mathrm{cm}$ y en la zona pelágica fue de 1964-2030 $\mu \mathrm{S} / \mathrm{cm}$; y para el $\mathrm{pH}$, la variación en la zona litoral fue de 7.99-8.85 y en la zona pelágica fue de 8.53-9.02. Se concluye que las comunidades acuáticas presentaron una moderada riqueza de especies durante el tiempo de evaluación.

Palabras claves: Comunidades acuáticas, Laguna Aricota.

\section{ABSTRACT}

The Aricota lake has remained "biologically" stable in recent years despite the extraction of water by the hydroelectric plants (Aricota I and II) and the decrease on its tributaries inflow (Callazas and Salado rivers). The purpose of the work is to identify the different aquatic communities (phytoplankton, periphyton, zooplankton, benthic macroinvertebrates and fish). The study was carried out for five months, at 5 sampling stations in late 2017 and early 2018 throughout the coastal and pelagic zone of the lake. In the results, phytoplankton are represented by 52 morphospecies distributed in: 6 Phyllum, 26 orders and 31 families; the periphyton with 56 morphospecies distributed in: 8 Phyllum, 25 orders and 34 families; zooplankton with 13 morpho-species distributed in: 6 Phyllum, 8 orders and 11 families; the macroinvertebrates are represented by 24 species distributed in: 5 Phyllum, 9 orders and 16 families and the ichthyofauna is represented by Oncorhynchus mykiss and Trichomycterus sp. The physical-chemical parameters present average values of: temperature in the coastal zone of the Aricota lagoon (HBO1, $\mathrm{HBO} 2, \mathrm{HBO} 3$ and $\mathrm{HBO} 4)$ was $18.0-18.2^{\circ} \mathrm{C}$, while in the pelagic zone (HBO5) it was $17.9-18.2^{\circ} \mathrm{C}$; in the case of dissolved oxygen, the variation in the coastal zone was 7.14-7.24 mg / L and in the pelagic zone it was 7.21-7.24 $\mathrm{mg} / \mathrm{L}$. For electrical conductivity, the variation in the littoral zone was 1960-2031 $\mathrm{SS} / \mathrm{cm}$; and, in the pelagic zone, it was $1964-2030 \mu \mathrm{S} / \mathrm{cm}$. For Ph, the variation in the littoral zone was 7.99-8.85; and, in the pelagic zone, it was 8.53-9.02. It is concluded that the aquatic communities present moderate species richness during the evaluation time.

Keywords: Aricota Lagoon, Aquatic Communities.

${ }^{1}$ Herbario Takana, Universidad Nacional Jorge Basadre Grohmann. Tacna, Perú.

${ }^{2}$ Laboratorio de Botánica. Universidad Nacional Jorge Basadre Grohmann. Tacna, Perú.

${ }^{3}$ Oficina de Transferencia e Innovación - Vicerrectorado de Investigación. Universidad Nacional Jorge Basadre Grohmann.

* Autor de correspondencia: prfrancov@gmail.com 


\section{INTRODUCCIÓN}

Los estudios limnológicos sobre calidad o estado trófico del agua parten del principio de que a cada tipo de ecosistema acuático está asociada una comunidad particular de organismos (Margalef, 1983; Roldán, 1992). En monitoreos biológicos, se analizan las especies presentes en los sistemas acuáticos, tales como: fitoplancton, perifiton, macrofitas, zooplancton, macroinvertebrados y peces (Figueroa et al., 2016). Por otro lado, Market et al. (2003) comentan que la salud de un ecosistema acuático se ve afectada cuando se excede su capacidad para absorber el estrés; el concepto propone que la salud ambiental de los ecosistemas acuáticos se puede evaluar mediante monitoreo biológico, utilizando organismos (comunidades acuáticas) como herramientas de diagnóstico.

El estudio de las comunidades del fitoplancton, a través de las asociaciones de especies, señala que son líneas a seguir para la caracterización de los diferentes tipos de lagos (Vicente et al., 2005). Las distribuciones de muchas especies de diatomeas (Bacillariophyta) están estrechamente relacionadas con condiciones limnológicas específicas, como el pH (Moss, 2010), la salinidad, los niveles de nutrientes, etc. (Likens, 2010).

Según Bellinger y Sigee (2010), las ventajas de la utilización de las diatomeas como organismos indicadores de calidad del agua son: se encuentran en cualquier lugar de cuerpos de agua (dulce y marino); algunas son muy sensibles a factores ambientales (contaminación), mientras que otras son muy tolerantes; responden a los cambios ambientales a corto y largo plazo; y son fácilmente colectables.

El perifiton es importante en ecosistemas acuáticos, ya que contribuyen a la fijación de carbono, al ciclo de nutrientes y es un gran indicador de los cambios ocurridos en un ambiente acuático (Hillebrand et al., 2008). Por otro lado, las algas perifíticas son moduladores químicos de los ecosistemas acuáticos, donde transforman muchos productos inorgánicos a formas orgánicas (nitrógeno), además, son estabilizadoras de muchos sustratos en medios acuáticos (Stevenson, 1996).

El crecimiento del zooplancton en los lagos naturales es alto, pero las fluctuaciones están fuertemente influenciadas por la disponibilidad de recursos y los cambios en las presiones de depredación (O'Sullivan y Reynolds, 2004).

Los macroinvertebrados acuáticos han adquirido importancia en el análisis de la calidad del agua, debido a que no solo revelan las condiciones ambientales actuales, sino que actúan como reveladores de las condiciones en el tiempo (AlbaTercedor, 1996). Se deduce que los macroinvertebrados se ven afectados en calidad, cantidad y distribución de los cuerpos de agua (O'Sullivan y Reynolds, 2004). El sustrato, la abundancia de macrófitos, la conductividad, la profundidad del agua y el detrito se relacionan con la diversidad y distribución de los macroinvertebrados (Likens, 2010), actuando como monitoreadores continuos del lugar que habitan (Pavé y Marchese, 2005).

Los peces son considerados como un vector de comunicación útil para sensibilizar sobre la preservación de la calidad de ríos y lagos (Cowx y Collares-Pereira, 2002), su caracterización resulta importante porque son reconocidas como buena herramienta ambiental (Angermeier y Schlosser, 1995 y Boulton, 1999) y como índices de la calidad del medio acuático (Oberdorff et al., 2002), capaces de indicar diversos niveles de degradación (Wichert y Rapport, 1998).

Los lagos y lagunas son sistemas abiertos y continuos que forman parte de una unidad mayor que incluye cuenca de drenaje e intercambio con la atmósfera (Roldán y Ramírez, 2008). Los lagos se han formado, regularmente, en las altas montañas por deshielo o movimientos tectónicos; en cambio, las lagunas se han formado en las partes bajas de los ríos por procesos de inundación o acción conjunta entre el mar y los ríos (Roldán y Ramírez, 2008).

En el departamento de Tacna existen cuatro cuencas: Locumba, Maure, Sama y Caplina. La cuenca Locumba cuenta con las lagunas: Suches, Vizcachas y Aricota. La cuenca Locumba se encuentra limitada por cadenas de cerros que, en dirección al Océano Pacífico, muestran un descenso sostenido y rápido del nivel de cumbres (ANA, 2012). Tiene dos lagunas de importancia: Suches y Aricota, estas regulan la oferta hídrica durante el periodo de estiaje (caudal mínimo en un río) (ANA, 2016).

La laguna Aricota (Fig. 1) se encuentra ubicada en la subcuenca Curibaya-Aricota, situada en los distritos de Curibaya y Quilahuani, provincia de Candarave, a $2771.44 \mathrm{~m}$ s. n. m. (EGESUR, $2017 \mathrm{~b}$ ), con un área de superficie de $1456 \mathrm{Km}^{2}$ (EGESUR, 2017a). Los afluentes que alimentan a la laguna Aricota son los ríos Salado y Callazas. El río Callazas nace en la laguna Suches y es el principal afluente de la laguna. Por otro lado, el río Salado nace en los ríos Jarume y Calientes, y presenta la mayor concentración de sales. La laguna Aricota es pieza clave por su aprovechamiento eléctrico, con las centrales hidroeléctricas Aricota I y II (Cutipa, 2014; Escalante, 2016). 


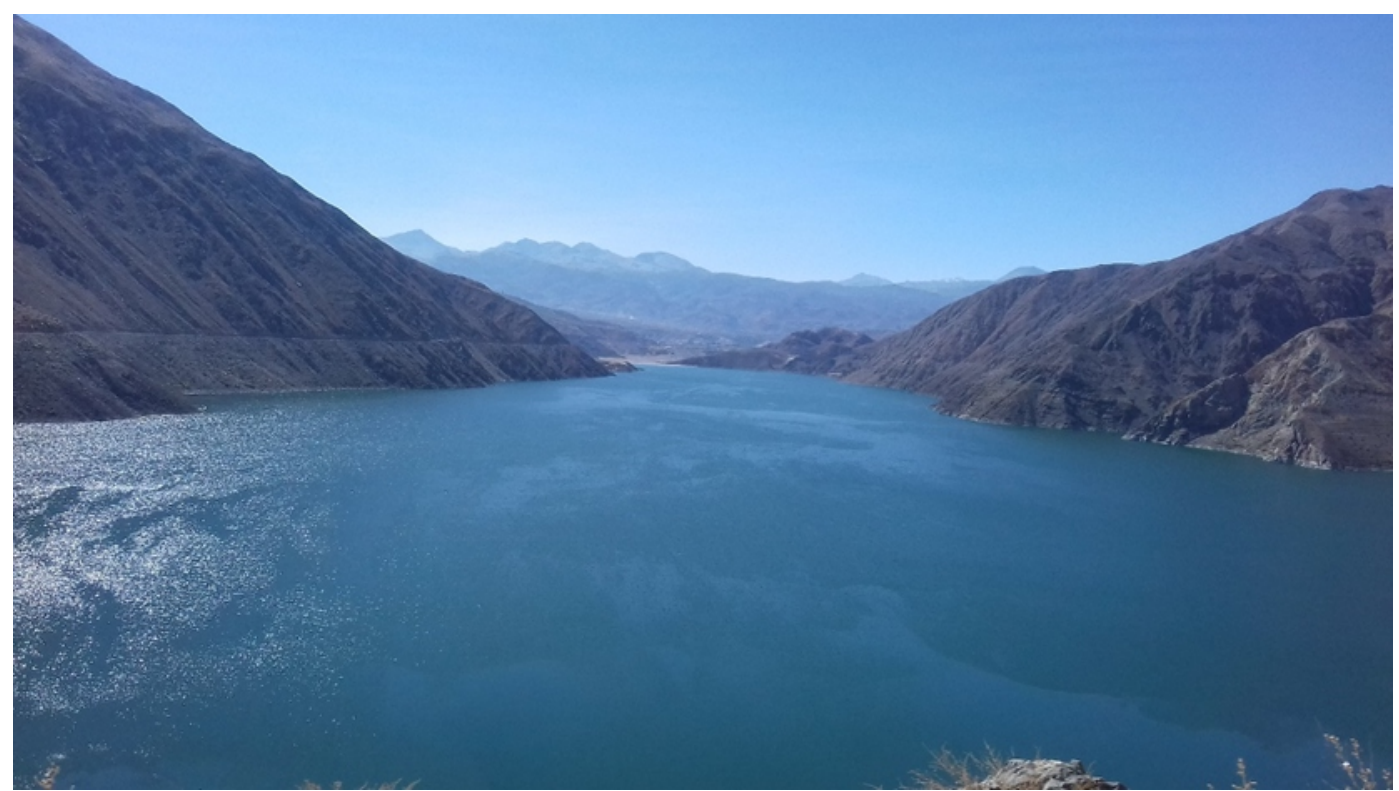

Figura 1. Vista panorámica de la laguna Aricota

Aunque en los últimos años se ha dado una recuperación lenta a comparación del nivel más bajo que alcanzó; primero por las limitaciones de agua por las cabeceras de cuenca, segundo por el proyecto de construcción de la central hidroelectrica Aricota III.

En la laguna Aricota, se trabajó con la identificación de las comunidades hidrobiológicas (fitoplancton, perifiton, zooplancton, macroinvertebrados bentónicos y peces).

\section{MATERIAL Y MÉTODOS}

El presente trabajo se realizó en la zona litoral y pelágica de la laguna Aricota; fueron realizadas seis (06) colectas en los años 2017 y 2018, con cinco (05) estaciones en cada colecta (Tablas 1 y 2, Figura 2). En la estación HBO5 no se realizó la colecta de perifiton y macroinvertebrados bentónicos, por ser estos exclusivos de la zona litoral de un cuerpo de agua.

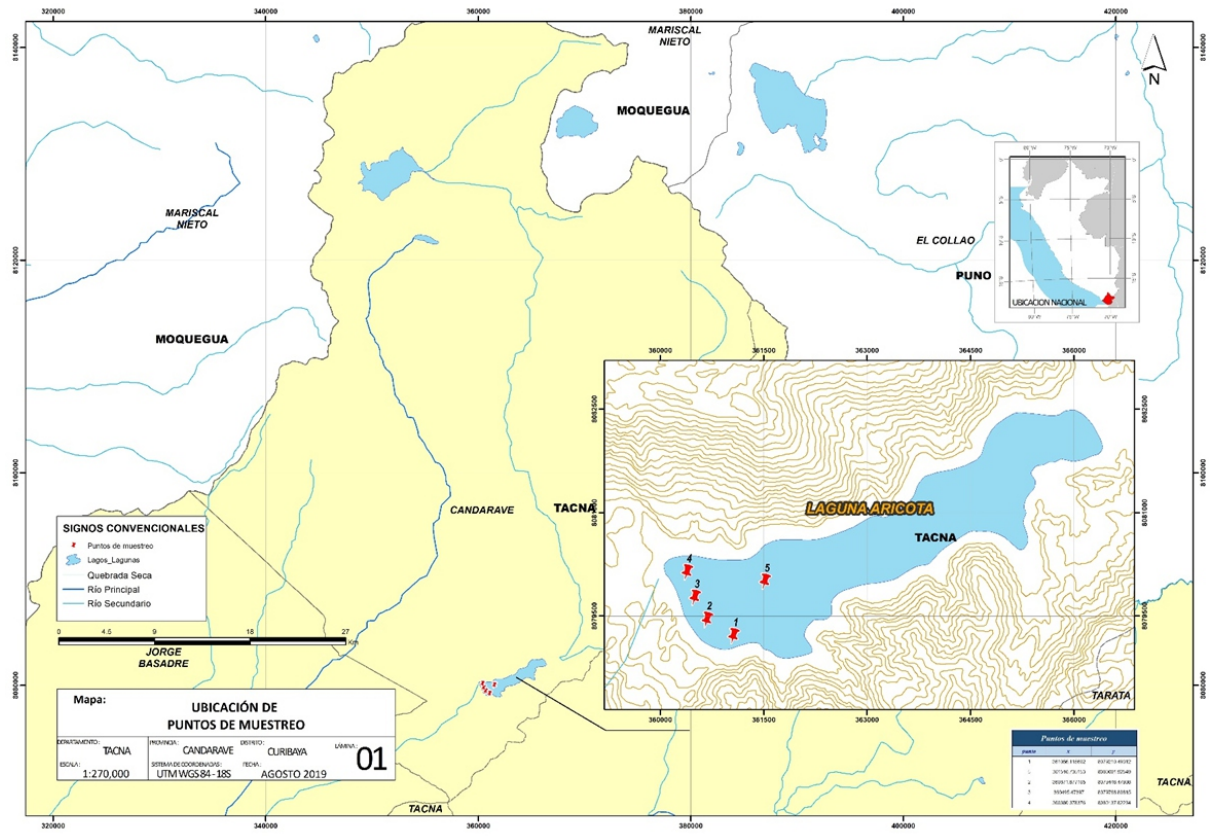

Figura 2. Mapa de ubicación de las estaciones de muestreo en la laguna Aricota (Zona litoral: $\mathrm{HBO} 1, \mathrm{HBO} 2, \mathrm{HBO} 3$ y HBO4; Zona pelágica: $\mathrm{HBO}$ ) 
Tabla 1. Estaciones de muestreo de la laguna Aricota

\begin{tabular}{|c|c|c|c|c|c|c|c|}
\hline Estación & Zona & Coordenadas & $\mathbf{F}$ & $\mathrm{Pe}$ & $\mathbf{z}$ & $\mathbf{M b}$ & $\mathbf{P}$ \\
\hline & & $17^{\circ} 22^{\prime}$ & & & & & \\
\hline HBO1 & Litoral & $\begin{array}{c}11.3^{\prime \prime S ~} 70^{\circ} 18^{\prime} \\
16.5^{\prime \prime} \mathrm{W}\end{array}$ & $\checkmark$ & $\checkmark$ & $\checkmark$ & $\checkmark$ & $\checkmark$ \\
\hline $\mathrm{HBO} 2$ & Litoral & $\begin{array}{c}17^{\circ} 22^{\prime} 8.3^{\prime \prime} \\
\text { S } 70^{\circ} 18^{\prime} 40^{\prime \prime} \mathrm{W}\end{array}$ & $\checkmark$ & $\checkmark$ & $\checkmark$ & $\checkmark$ & $\checkmark$ \\
\hline $\mathrm{HBO} 3$ & Litoral & $\begin{array}{c}17^{\circ} 21^{\prime} 55.3^{\prime \prime} \\
\text { S } 70^{\circ} 18^{\prime} 52.2^{\prime \prime} \\
\text { W }\end{array}$ & $\checkmark$ & $\checkmark$ & $\checkmark$ & $\checkmark$ & $\checkmark$ \\
\hline $\mathrm{HBO} 4$ & Litoral & $\begin{array}{c}17^{\circ} 21^{\prime} 39.9^{\prime \prime} \\
\text { S } 70^{\circ} 19^{\prime} 0.4^{\prime \prime} \\
\text { W }\end{array}$ & $\checkmark$ & $\checkmark$ & $\checkmark$ & $\checkmark$ & $\checkmark$ \\
\hline HBO5 & Pelágica & $\begin{array}{c}17^{\circ} 21^{\prime} 43.5^{\prime \prime} \\
\text { S } 70^{\circ} 18^{\prime} 14.3^{\prime \prime} \\
\text { W }\end{array}$ & $\checkmark$ & --- & $\checkmark$ & --- & $\checkmark$ \\
\hline $\begin{array}{l}\mathrm{F}: \text { Fitopla } \\
\text { Pe: Perifitc } \\
\mathrm{Z}: \text { Zoopla } \\
\mathrm{Mb}: \text { Macrc } \\
\mathrm{P}: \text { Peces }\end{array}$ & $\begin{array}{l}\text { ton } \\
\text { nvertebra }\end{array}$ & s bentónicos & & & & & \\
\hline
\end{tabular}

Tabla 2. Fechas de monitoreo de la laguna Aricota

\begin{tabular}{cc|}
\hline Monitoreo & Fecha \\
\hline 1 & $26 / 08 / 2017$ \\
\hline 2 & $18 / 11 / 2017$ \\
\hline 3 & $17 / 02 / 2018$ \\
\hline 4 & $21 / 04 / 2018$ \\
\hline 5 & $21 / 07 / 2018$ \\
\hline 6 & $27 / 10 / 2018$ \\
\hline
\end{tabular}

\section{Parámetros fisicoquímicos}

La medida de los parámetros (oxígeno disuelto, conductividad eléctrica, $\mathrm{pH}$ y temperatura) se realizó con el multiparámetro portátil $\mathrm{HACH}$ HQ40d.

\section{Colecta}

El muestreo de fitoplancton se realizó mediante el filtrado de 60 litros de agua a través de la red de plancton (porosidad de $20 \mu \mathrm{m})$ (Branco, 1978). Una vez colectadas las muestras, la red fue lavada a la brevedad posible, usando agua tibia y un cepillo de cerdas suaves (Ferrario et al., 1995) para no estropear la malla. En el caso del muestreo en la zona pelágica de la laguna Aricota, se realizó la colecta sumergiendo la red de plancton, usando un bote que fue prestado por los criadores de truchas. Las muestras filtradas fueron colocadas en un colector de plástico con capacidad de $100 \mathrm{ml}$ y se conservaron usando formol al $4 \%$ (Ferrario et al., 1995), previo etiquetado (fecha/estación de muestreo). Para obtener una alta representatividad, se realizó un muestreo integrado como lo sugiere Blomqvist (2001).

El perifiton fue colectado, siguiendo las recomendaciones de Cambra et al. (2005) y Stevenson \& Rollins (2007). El cepillado de piedras fue en un área equivalente a $20 \mathrm{~cm}^{2}$. Después, se enjuagó el raspado con agua y se colocó la muestra en un envase $(100 \mathrm{ml})$, se conservaron usando formol al $4 \%$ (Ferrario et al., 1995), previo etiquetado.

El zooplancton fue colectado en la zona litoral y pelágica de la laguna Aricota. Para las muestras de la zona litoral, se realizó un filtrado de 60 litros al igual que el fitoplancton con una red $(50 \mu \mathrm{m})$. En la zona pelágica, se realizó la colecta sumergiendo la red al igual como en la colecta de fitoplancton, empleando un bote.

Los macroinvertebrados bentónicos fueron colectados solo en la zona litoral de la laguna Aricota, siguiendo recomendaciones de AlbaTercedor, Pardo, Prat y Pujante (2005). Se empleó una red surber, realizando un recogido o barrido aproximadamente a $1 \mathrm{~m}$ cerca del fondo y subiendo hasta la superficie de la laguna. Para después separar las muestras colectadas de sedimento con un tamiz (criba) de $100 \mu \mathrm{m}$. Las muestras fueron contenidas en un envase de plástico $(250 \mathrm{ml})$ y se conservaron usando alcohol al $70 \%$ (Alba-Tercedor et al., 2005). 
Los peces fueron colectados en la zona litoral y pelágica de la laguna Aricota, siguiendo recomendaciones de Sostoa et al. (2005). Fue reportada la existencia de Trichomycterus, según el estudio realizado por Moran (2018), en la laguna Aricota. En la zona litoral, se empleó una red de muestreo sumergiendo y moviendo las zonas rocosas. Para su conservación, se usó formol al $4 \%$ por $48 \mathrm{~h}$, después, se usó alcohol al $70 \%$ (Sostoa et al. 2005); se mantuvieron los ejemplares en un envase de plástico de $(500 \mathrm{ml})$.

\section{Cuantificación}

Se realizó la cuantificación de las muestras de fitoplancton usando la cámara de SedgwickRafter, como lo describe Serfling (1949) y McAlice (1971). Antes de hacer un recuento, se tomó una muestra cualitativa (Schwoerbel, 1966). Los colectores se agitaron uniformemente durante 1-2 minutos, por recomendación de Jairo (2000). El número de campos que fueron contados fue de 30, como lo recomienda Villafañe y Reid (1995). Las claves utilizadas para la identificación de las morfoespecies fueron: Streble y Krauter (1987), Round et al. (1990), Hartley et al. (1996), LangeBertalot et al. (1998), Domínguez y Fernández (1999) y Bellinger y Sigee (2010).

Para la cuantificación del perifiton, se usó la cámara de Sedgwick-Rafter, al igual que en el fitoplancton. Los resultados preliminares son expresados en organismos/ml, mediante la siguiente fórmula (APHA, 2012):

$$
\mathrm{Org} / \mathrm{mm}^{2}=\frac{N \times A_{t} \times V_{t}}{A_{c} \times V_{s} \times A_{c}}
$$

$N=$ número de organismos contados

$A t=$ superficie total de fondo de la cámara $\left(\mathrm{mm}^{2}\right)$

$V t=$ volúmen total de suspensión de la muestra original $(\mathrm{ml})$

$A c=$ área de conteo (tiras o campos) $\left(\mathrm{mm}^{2}\right)$

$V S=$ volúmen de la muestra utilizada en la cámara $(\mathrm{ml})$ $A s=$ superficie del área del sustrato $\left(\mathrm{mm}^{2}\right)$

En el caso del zooplancton, se usó la cámara de Sedgwick-Rafter, al igual como en el conteo del fitoplancton y perifiton. Los colectores se agitaron uniformemente durante 1-2 minutos, por recomendación de Jairo (2000).
Las claves utilizadas fueron: Smirnov (1992 y 1996), Segers (1995) y Kotov y Ŝtifter (2006).

Los resultados preliminares son expresados en organismos/L, mediante la siguiente formula (APHA, 2012):

$$
\operatorname{Org} / m^{3}=\frac{C x V^{\prime}}{V^{\prime \prime} \times V^{\prime \prime \prime}}
$$

$C=$ número de organismos contados

$V^{\prime}=$ volumen concentrado de la muestra $(\mathrm{mL})$

$V^{\prime \prime}=$ volumen contado $(\mathrm{mL})$

$V^{\prime \prime \prime}=$ Volumen filtrado para la muestra $\left(\mathrm{m}^{3}\right)$

En el Herbario Takana de la Facultad de Ciencias y en la División de Limnología de CORBIDILima, se realizó la cuantificación e identificación de las muestras. Primero, se procedió a limpiar la muestra colectada empleando un tamiz, para después seleccionar una alicuota de lo tamizado para su observación y conteo en el estereoscopio (Micros Austria). Las claves utilizadas fueron: Roldán (1996), Ruiz-Moreno et al. (2000), Domínguez y Fernández (2009) y Prat et al. (2011).

La identificación se realizó en el Museo de Historia Natural de San Marcos y la División de Limnología de CORBIDI. La clave utilizada para la identificación de las morfoespecies fue Burges (1993).

\section{RESULTADOS}

La temperatura más alta en la zona litoral se da en la estación HBO1 $\left(18.6{ }^{\circ} \mathrm{C}\right)$ en el mes de febrero de 2018, y la más baja $\left(18.0^{\circ} \mathrm{C}\right)$ en $\mathrm{HBO} 2$; mientras que en la zona pelágica (HBO5), la temperatura más alta fue de 18.2 durante febrero y abril de 2018, y la más baja de $17.9{ }^{\circ} \mathrm{C}$ en noviembre de 2017 (Fig. 3a).

El valor de oxígeno disuelto más alto en la zona litoral se da en las estaciones HBO3 y HBO4 (7.24 $\mathrm{mg} / \mathrm{L}$ ) en el mes de noviembre de 2017, y la más baja (7.14 mg/L) en HBO1 en febrero de 2018. Mientras que en la zona pelágica (HBO5), la más alta fue de $7.24 \mathrm{mg} / \mathrm{L}$ en noviembre de 2017; y la más baja en abril de 2018 con $7.21 \mathrm{mg} / \mathrm{L}$ (Fig. 3b). La Fig. 3c muestra que no existe una variación 
significativa en los meses de monitoreo. El valor de conductividad eléctrica más alto en la zona litoral se da en las estaciones HBO2 $(2022 \mu \mathrm{S} / \mathrm{cm})$ en el mes de julio-2018, y la más baja (1960 $\mu \mathrm{S} / \mathrm{cm}$ ) en octubre-2018. Mientras que en la zona pelágica (HBO5), la más alta fue de $2030 \mu \mathrm{S} / \mathrm{cm}$ en agosto de 2017, y la más baja en noviembre2017 con $1964 \mu \mathrm{S} / \mathrm{cm}$.
La Fig. $3 \mathrm{~d}$ muestra que el valor de $\mathrm{pH}$ más alto en la zona litoral se da en las estaciones HBO4 (9.01) en el mes de noviembre de 2017, y el más bajo (7.99) en HBO4 en febrero de 2018. Mientras que en la zona pelágica (HBO5), el más alto fue de 9.02 en agosto de 2017, y el más bajo fue en febrero de 2018 con 8.53 .
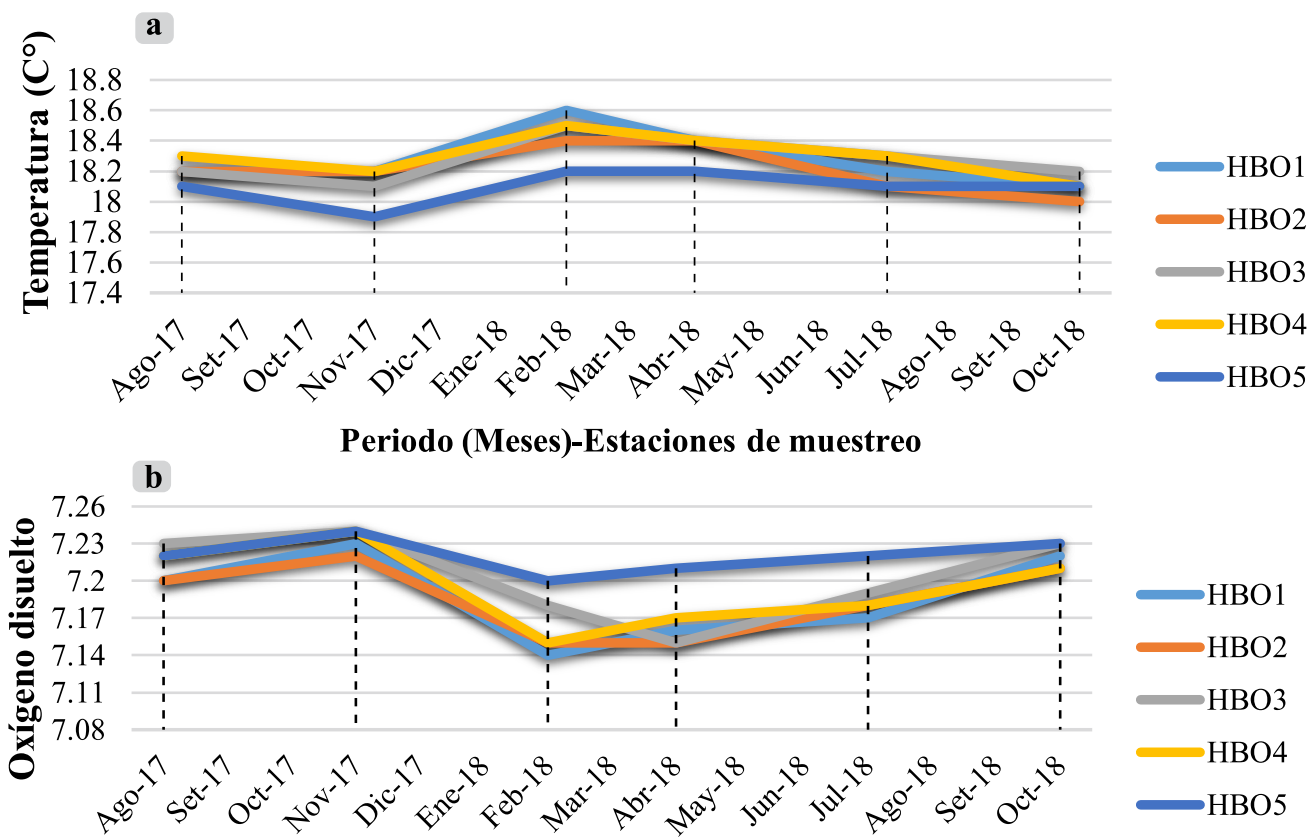

c

Período (Meses)-Estaciones de muestreo

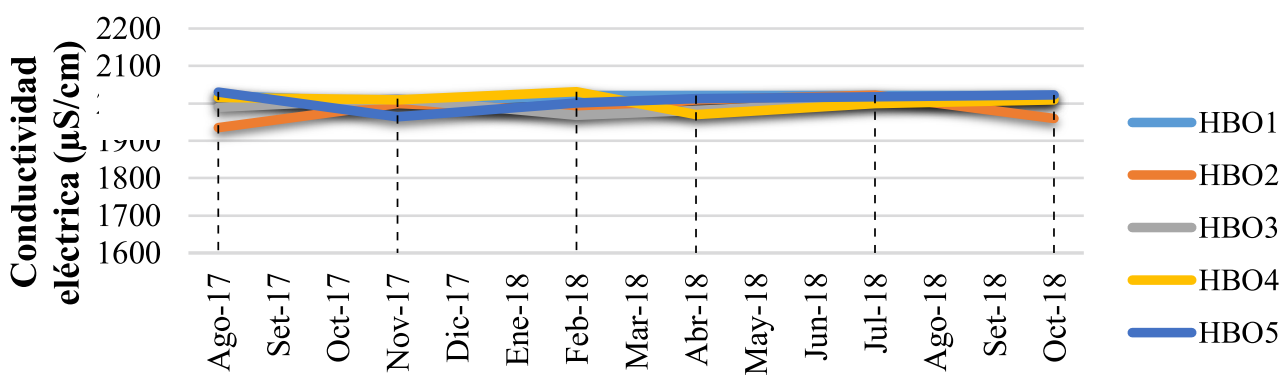

Período (Meses)-Estaciones de muestreo

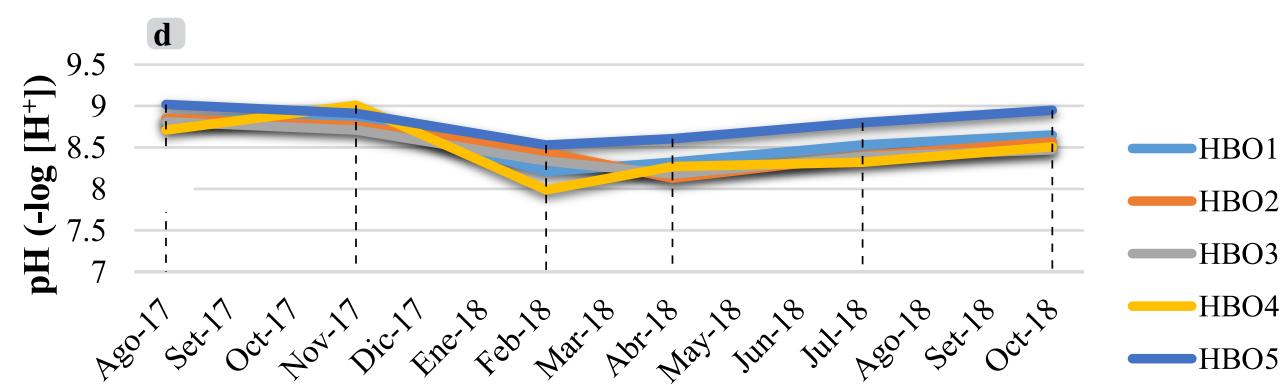

Período (Meses)-Estaciones de muestreo

Figura 3. Variación de parámetros fisicoquímicos en la laguna Aricota. a) Temperatura b) Oxígeno disuelto c) Conductividad eléctrica d) $\mathrm{pH}$ 
Se identificaron las muestras colectadas de la zona litoral ( $\mathrm{HBO} 1, \mathrm{HBO} 2, \mathrm{HBO} 3$ y HBO4) y pelágica (HBO5) de la laguna Aricota. Se encontraron hasta seis (06) Phyllum en las muestras de fitoplancton, conformados por: Bacillariophyta, Cyanobacteria, Chlorophyta, Chrysophyta, Cryptophyta y Euglenophyta. La Tabla 3 resume los valores de riqueza específica por Phyllum presentes en las muestras de fitoplancton en los 6 monitoreos a la laguna Aricota. Se contó el mayor número de especies (55) en la zona litoral en el cuarto monitoreo. El menor número (44) fue en el segundo monitoreo. En la zona pelágica, el número máximo de especies identificadas fue de 53 en el cuarto monitoreo, y el menor número fue de 48 en el segundo monitoreo.

Tabla 3. Riqueza de especies de las comunidades del fitoplancton - laguna Aricota

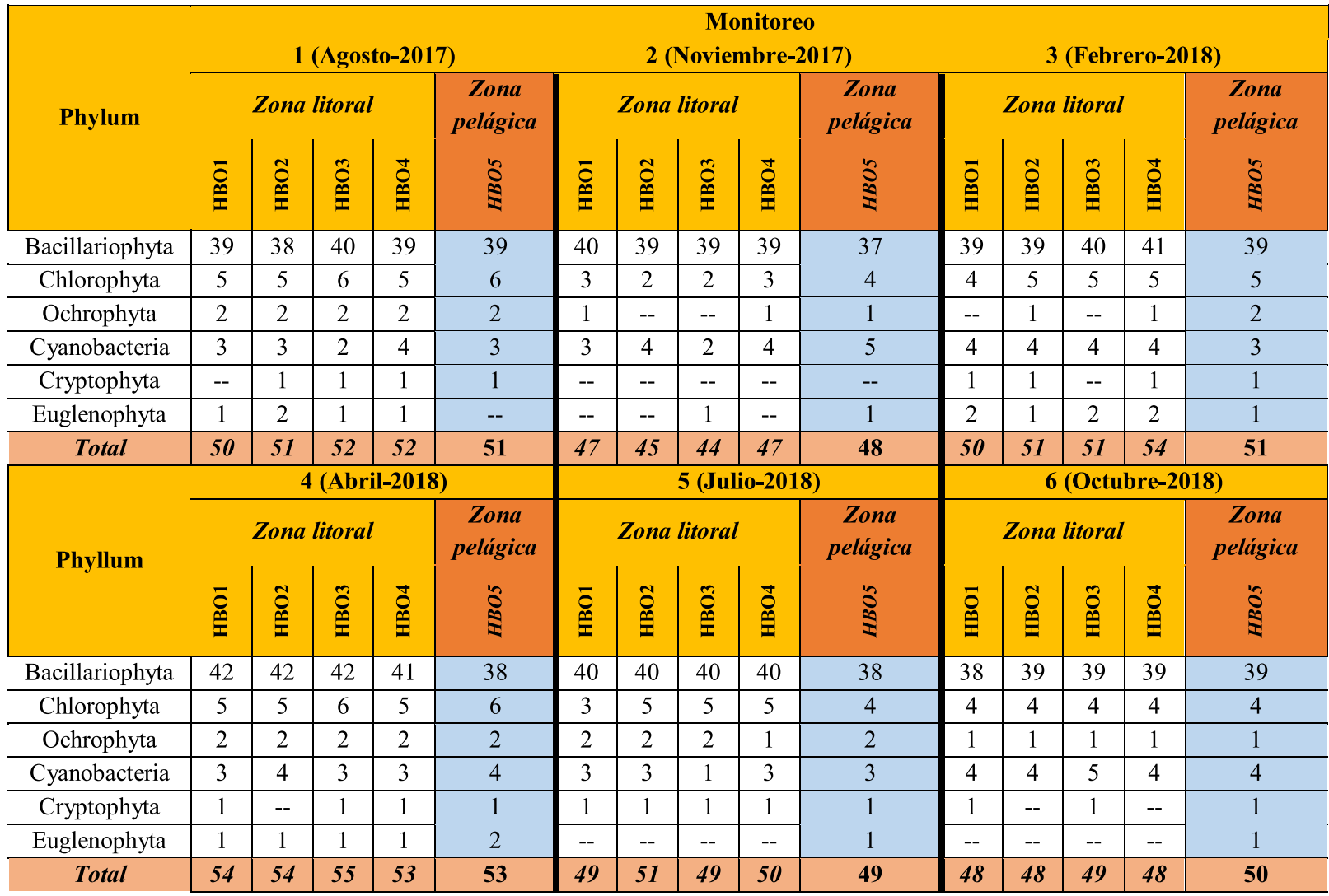

A diferencia de fitoplancton, cuyo muestreo se realizó en todos los puntos (HBO1, $\mathrm{HBO} 2$, HBO3, HBO4 y HBO5) que comprenden la zona litoral y pelágica de la laguna Aricota, en el caso de perifiton solo se realizó el muestreo en la zona litoral de la laguna, exceptuando así el punto HBO5. Se identificaron hasta nueve (09) Phyllum componentes del perifiton, para las 4 estaciones de muestreo (HBO1, HBO2, $\mathrm{HBO} 3$ y $\mathrm{HBO} 4)$, conformados por: Bacillariophyta, Cyanobacteria, Chlorophyta, Ochrophyta, Euglenophyta, Amoebozoa, Percolozoa, Cercozoa y Ciliophora. La Tabla 4 resume que el número de especies en la zona litoral de la laguna Aricota. En el primer monitoreo, se hallaron el mayor número de especies (56), en la estación HBO2. En el cuarto y sexto monitoreo, se encontraron el menor número, el cual fue de 51 especies en las estaciones $\mathrm{HBO} 2, \mathrm{HBO} 3$ y $\mathrm{HBO} 4$. 
Tabla 4. Riqueza de especies de las comunidades del perifiton - laguna Aricota

\begin{tabular}{|c|c|c|c|c|c|c|c|c|c|c|c|c|}
\hline \multirow{3}{*}{ Phylum } & & \multicolumn{10}{|c|}{ Monitoreo } & \\
\hline & \multicolumn{4}{|c|}{ Zona litoral } & \multicolumn{4}{|c|}{ Zona litoral } & \multicolumn{4}{|c|}{ Zona litoral } \\
\hline & 曾 - & $\stackrel{\circ}{\stackrel{\rho}{*} N}$ & 욜 & 욜 + & 을 - & 兽 & 睪m & 욜 + & 总 - & 울 & 曾m & 畨 + \\
\hline Bacillariophyta & 38 & 38 & 38 & 38 & 37 & 35 & 36 & 36 & 38 & 38 & 38 & 38 \\
\hline Chlorophyta & 7 & 7 & 6 & 7 & 6 & 6 & 6 & 6 & 6 & 7 & 7 & 7 \\
\hline Euglenophyta & 2 & 2 & 1 & 2 & 2 & 2 & 2 & 2 & 1 & 2 & 1 & 2 \\
\hline Cyanobacteria & 1 & 1 & 1 & -- & 2 & 2 & 2 & 2 & -- & -- & -- & -- \\
\hline Ochrophyta & 1 & 1 & 1 & -- & 1 & 1 & 1 & 1 & -- & -- & -- & -- \\
\hline Amoebozoa & 3 & 3 & 3 & 3 & 3 & 2 & 2 & 2 & 3 & 3 & 3 & 3 \\
\hline Percolozoa & 2 & 2 & 2 & 2 & 2 & 2 & 1 & 2 & 2 & 2 & 2 & 2 \\
\hline Cercozoa & 1 & 1 & 1 & 1 & 1 & 1 & 1 & 1 & 1 & 1 & 1 & 1 \\
\hline Ciliophora & -- & 1 & 1 & 1 & 1 & 1 & 1 & 1 & 1 & 1 & 1 & 1 \\
\hline Total & 54 & 56 & 54 & 54 & 55 & 52 & 52 & 53 & 52 & 54 & 53 & 54 \\
\hline \multirow[b]{3}{*}{ Phyllum } & \multicolumn{4}{|c|}{4 (Abril-2018) } & \multicolumn{4}{|c|}{5 (Julio-2018) } & \multicolumn{4}{|c|}{6 (Octubre-2018) } \\
\hline & \multicolumn{4}{|c|}{ Zona litoral } & \multicolumn{4}{|c|}{ Zona litoral } & \multicolumn{4}{|c|}{ Zona litoral } \\
\hline & 을 - & 曾 N & 睪m & $\stackrel{\circ}{\stackrel{\rho}{1}+}$ & $\stackrel{\circ}{\stackrel{p}{ت} \text { - }}$ & $\stackrel{\circ}{*} \sim$ & 睪m & $\stackrel{\circ}{\stackrel{P}{1}}+$ & 욜 - & $\stackrel{\circ}{.0} N$ & 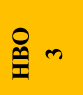 & 욥 \\
\hline Bacillariophyta & 38 & 37 & 38 & 37 & 38 & 38 & 38 & 38 & 37 & 36 & 36 & 37 \\
\hline Chlorophyta & 6 & 6 & 6 & 6 & 5 & 7 & 7 & 6 & 6 & 6 & 7 & 6 \\
\hline Euglenophyta & 1 & 1 & 1 & 1 & 1 & 1 & 1 & 2 & 2 & 2 & 2 & 2 \\
\hline Cyanobacteria & -- & -- & -- & -- & 1 & 1 & 1 & 1 & 2 & 2 & 2 & 2 \\
\hline Ochrophyta & 1 & 1 & 1 & 1 & 1 & 1 & 1 & 1 & 1 & -- & 1 & 1 \\
\hline Amoebozoa & 3 & 3 & 1 & 2 & 1 & 2 & 1 & 1 & -- & -- & -- & -- \\
\hline Percolozoa & 1 & 2 & 2 & 2 & 1 & 1 & -- & 1 & 2 & 2 & 1 & 1 \\
\hline Cercozoa & 1 & 1 & 1 & 1 & 1 & 1 & 1 & 1 & 1 & 1 & 1 & 1 \\
\hline Ciliophora & 1 & -- & 1 & 1 & 1 & 1 & 1 & 1 & 1 & 1 & 1 & 1 \\
\hline Total & 52 & 51 & 51 & 51 & 51 & 53 & 52 & 52 & 52 & 52 & 52 & 51 \\
\hline
\end{tabular}

Se identificaron las muestras colectadas de la zona litoral (HBO1, HBO2, HBO3 y HBO4) y pelágica (HBO5) de la laguna Aricota. Se identificaron hasta nueve (09) Phyllum componentes del zooplancton, para las 5 estaciones de muestreo, conformado por: Bacillariophyta, Cyanobacteria, Chlorophyta, Ochrophyta, Euglenophyta,
Amoebozoa, Percolozoa, Cercozoa y Ciliophora. La Tabla 5 resume que el número de especies en la zona pelágica fue mayor a comparación de la zona litoral. En el tercer y cuarto monitoreo se encuentra el mayor número de especies (13); y en el primer monitoreo, el menor número de especies (5). 
Tabla 5. Riqueza de especies de las comunidades del zooplancton - laguna Aricota

\begin{tabular}{|c|c|c|c|c|c|c|c|c|c|c|c|c|c|c|c|}
\hline \multirow{4}{*}{ Phylum } & \multicolumn{15}{|c|}{ Monitoreo } \\
\hline & \multicolumn{5}{|c|}{1 (Agosto-2017) } & \multicolumn{5}{|c|}{2 (Noviembre-2017) } & \multicolumn{5}{|c|}{3 (Febrero-2018) } \\
\hline & \multicolumn{4}{|c|}{ Zona litoral } & \multirow{2}{*}{$\begin{array}{c}\begin{array}{c}\text { Zona } \\
\text { pelágica }\end{array} \\
\vdots \\
\vdots\end{array}$} & \multicolumn{4}{|c|}{ Zona litoral } & \multirow{2}{*}{\begin{tabular}{c}
$\begin{array}{c}\text { Zona } \\
\text { pelágica }\end{array}$ \\
\hdashline \\
$\wp$
\end{tabular}} & \multicolumn{4}{|c|}{ Zona litoral } & \multirow{2}{*}{\begin{tabular}{c} 
Zona \\
pelágica \\
$\vdots$ \\
$\vdots$ \\
\hdashline
\end{tabular}} \\
\hline & $\begin{array}{l}\overline{0} \\
0 \\
0\end{array}$ & 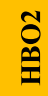 & 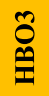 & $\begin{array}{l}\text { ठ } \\
\text { 苞 }\end{array}$ & & $\begin{array}{l}\bar{\delta} \\
\text { O. }\end{array}$ & $\begin{array}{l}\text { Oొ } \\
\text { 茥 }\end{array}$ & $\begin{array}{l}\text { ô } \\
\text { 茥 }\end{array}$ & $\begin{array}{l}\text { 足 } \\
\stackrel{0}{\underline{I}}\end{array}$ & & $\begin{array}{l}\overline{0} \\
0 \\
0\end{array}$ & $\begin{array}{l}\text { Oే } \\
0 \\
\underline{I}\end{array}$ & 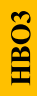 & $\begin{array}{l}\text { ठ } \\
\text { 茥 }\end{array}$ & \\
\hline Amoebozoa & 2 & 2 & 2 & 2 & 2 & 2 & 2 & 2 & 2 & 1 & 2 & 1 & 1 & 2 & 2 \\
\hline Cercozoa & 2 & 2 & 2 & 2 & 2 & 1 & 1 & 1 & -- & 2 & 2 & 2 & 2 & 3 & 3 \\
\hline Sarcomastigophora & 1 & 1 & 1 & 1 & 1 & 1 & 1 & 1 & 1 & 1 & 1 & 1 & 1 & 1 & 1 \\
\hline Rotifera & -- & -- & -- & -- & 1 & 1 & 1 & 1 & 1 & 1 & 1 & 1 & 1 & 1 & 1 \\
\hline Arthopoda & -- & -- & -- & -- & 3 & 3 & 2 & 3 & 3 & 4 & 4 & 4 & 4 & 4 & 5 \\
\hline Nematoda & --- & -- & -- & -- & -- & 1 & -- & 1 & 1 & 1 & -- & -- & -- & -- & 1 \\
\hline Total & 5 & 5 & 5 & 5 & 9 & 9 & 7 & 9 & 8 & 10 & 10 & 9 & 9 & 11 & 13 \\
\hline \multirow{3}{*}{ Phyllum } & \multicolumn{5}{|c|}{4 (Abril-2018) } & \multicolumn{5}{|c|}{5 (Julio-2018) } & \multicolumn{5}{|c|}{6 (Octubre-2018) } \\
\hline & \multicolumn{4}{|c|}{ Zona litoral } & $\begin{array}{c}\text { Zona } \\
\text { pelágica }\end{array}$ & \multicolumn{4}{|c|}{ Zona litoral } & $\begin{array}{c}\text { Zona } \\
\text { pelágica }\end{array}$ & \multicolumn{4}{|c|}{ Zona litoral } & $\begin{array}{c}\text { Zona } \\
\text { pelágica }\end{array}$ \\
\hline & $\begin{array}{l}\overline{0} \\
\text { 至 }\end{array}$ & 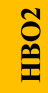 & 厄̂ & $\begin{array}{l}\text { ठ } \\
\text { 国 }\end{array}$ & $\begin{array}{l}\qquad \\
8\end{array}$ & $\begin{array}{l}\bar{D} \\
\text { 㒸 }\end{array}$ & $\begin{array}{l}\text { Ő } \\
\text { 至 }\end{array}$ & 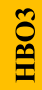 & $\begin{array}{l}\text { 足 } \\
\text { 至 }\end{array}$ & 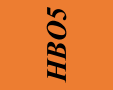 & $\begin{array}{l}\overline{0} \\
\underline{\underline{I}}\end{array}$ & 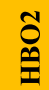 & 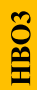 & $\begin{array}{l}\text { ठ } \\
\text { 稛 }\end{array}$ & $\stackrel{8}{8}$ \\
\hline Amoebozoa & 1 & 1 & 1 & 1 & 2 & 2 & 2 & 2 & 2 & 2 & 2 & 2 & 2 & 2 & 2 \\
\hline Cercozoa & 1 & 1 & 1 & 1 & 3 & 1 & 1 & 2 & 2 & 2 & 1 & 1 & 1 & 1 & 2 \\
\hline Sarcomastigophora & 1 & 1 & -- & 1 & 1 & 1 & 1 & 1 & 1 & 1 & 1 & 1 & 1 & 1 & 1 \\
\hline Rotifera & 1 & 1 & 1 & 1 & 1 & 1 & 1 & 1 & 1 & 1 & 1 & 1 & 1 & 1 & 1 \\
\hline Arthopoda & 4 & 5 & 5 & 5 & 5 & 1 & 3 & 3 & 3 & 4 & 2 & 2 & 2 & 3 & 4 \\
\hline Nematoda & 1 & 1 & 1 & 1 & 1 & -- & 1 & 1 & -- & -- & -- & -- & -- & -- & 1 \\
\hline Total & 9 & 10 & 9 & 10 & 13 & 6 & 8 & 10 & 9 & 10 & 8 & 8 & 8 & 9 & 11 \\
\hline
\end{tabular}

El muestreo se realizó al igual que el de perifiton en los puntos (HBO1, HBO2, $\mathrm{HBO} 3$ y $\mathrm{HBO} 4$ ) que comprenden la zona litoral de la laguna Aricota. Se identificaron hasta nueve (09) Phyllum componentes del fitoplancton, para las 4 estaciones de muestreo, conformado por:
Bacillariophyta, Cyanobacteria, Chlorophyta, Ochrophyta, Euglenophyta, Amoebozoa, Percolozoa, Cercozoa y Ciliophora. En el tercer y cuarto monitoreo, es mayor el número de especies (24); mientras que, en el sexto monitoreo se da el menor número de especies (14) (Tabla 6).

Tabla 6. Riqueza de especies de las comunidades del macroinvertebrados - laguna Aricota

\begin{tabular}{|c|c|c|c|c|c|c|c|c|c|c|c|c|}
\hline \multirow{4}{*}{ Phylum } & \multicolumn{12}{|c|}{ Monitoreo } \\
\hline & \multicolumn{4}{|c|}{1 (Agosto-2017) } & \multicolumn{4}{|c|}{2 (Noviembre-2017) } & \multicolumn{4}{|c|}{3 (Febrero-2018) } \\
\hline & \multicolumn{4}{|c|}{ Zona litoral } & \multicolumn{4}{|c|}{ Zona litoral } & \multicolumn{4}{|c|}{ Zona litoral } \\
\hline & $\begin{array}{l}\overline{0} \\
\text { 茴 }\end{array}$ & $\begin{array}{l}\text { Oี } \\
\text { 茥 }\end{array}$ & $\begin{array}{l}\text { Oొ } \\
\text { 茥 }\end{array}$ & $\begin{array}{l}\text { 巳 } \\
\text { 严 }\end{array}$ & $\begin{array}{l}\overline{0} \\
\text { 皇 }\end{array}$ & $\begin{array}{l}\text { Õ } \\
\text { Oૈ }\end{array}$ & $\begin{array}{l}\text { ô } \\
\text { 茥 }\end{array}$ & $\begin{array}{l}\text { さ゚ } \\
\text { Uૈ }\end{array}$ & $\begin{array}{l}\overline{0} \\
\text { 茥 }\end{array}$ & $\begin{array}{l}\text { Õ } \\
\text { Êં }\end{array}$ & 祭 & $\begin{array}{l}\text { ¿ } \\
\text { 首 }\end{array}$ \\
\hline Annelida & 1 & 2 & 1 & 2 & 2 & 1 & 1 & 1 & 1 & 1 & 1 & 2 \\
\hline Arthropoda & 7 & 8 & 10 & 9 & 9 & 9 & 9 & 9 & 19 & 19 & 21 & 20 \\
\hline Mollusca & 1 & 1 & 1 & 3 & 3 & 3 & 3 & 4 & -- & -- & -- & -- \\
\hline Nematoda & -- & -- & -- & -- & 1 & 1 & 1 & 1 & -- & -- & -- & -- \\
\hline Platyhelminthes & -- & -- & -- & -- & -- & -- & -- & -- & 1 & -- & -- & 1 \\
\hline Total & 11 & 11 & 12 & 14 & 15 & 14 & 14 & 15 & 21 & 20 & 22 & 22 \\
\hline \multirow{3}{*}{ Phyllum } & \multicolumn{4}{|c|}{4 (Abril-2018) } & \multicolumn{4}{|c|}{5 (Julio-2018) } & \multicolumn{4}{|c|}{6 (Octubre-2018) } \\
\hline & \multicolumn{4}{|c|}{ Zona litoral } & \multicolumn{4}{|c|}{ Zona litoral } & \multicolumn{4}{|c|}{ Zona litoral } \\
\hline & $\begin{array}{l}\overline{0} \\
\text { 茥 }\end{array}$ & 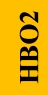 & $\begin{array}{l}\text { Oొ } \\
\text { Ê }\end{array}$ & 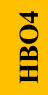 & $\begin{array}{l}\bar{\delta} \\
\text { 苩 }\end{array}$ & 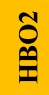 & $\begin{array}{l}\text { ô } \\
\text { 苩 }\end{array}$ & 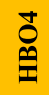 & $\begin{array}{l}\overline{0} \\
\text { 茴 }\end{array}$ & $\begin{array}{l}\text { Oొ } \\
\text { Ex }\end{array}$ & 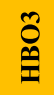 & 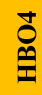 \\
\hline Annelida & 1 & 1 & 1 & 2 & 1 & 1 & 1 & 2 & 2 & 2 & 2 & 2 \\
\hline Arthropoda & 20 & 21 & 21 & 21 & 10 & 10 & 10 & 10 & 9 & 9 & 7 & 9 \\
\hline Mollusca & -- & -- & -- & -- & 1 & 2 & 1 & 2 & 3 & 3 & 3 & 3 \\
\hline Nematoda & -- & -- & -- & -- & -- & -- & -- & -- & -- & -- & -- & -- \\
\hline Platyhelminthes & 1 & 1 & -- & 1 & 1 & -- & -- & 1 & -- & -- & -- & -- \\
\hline Total & 22 & 23 & 22 & 24 & 13 & 13 & 12 & 15 & 14 & 14 & 12 & 14 \\
\hline
\end{tabular}


En el estudio, la evaluación de peces fue de manera cualitativa, realizándose el muestreo en la zona litoral y pelágica con red, encontrándose Oncorhynchus mykiss "trucha arco iris" y Trichomycterus sp. "bagre" (Tabla 7). Fue abundante Trichomycterus sp., en la zona litoral a diferencia de la zona pelágica. La ubicación taxonómica de estas especies es:

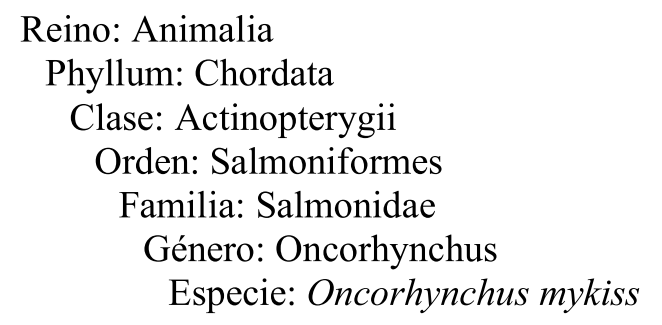

\author{
Reino: Animalia \\ Phyllum: Chordata \\ Clase: Actinopterygii \\ Orden: Siluriformes \\ Familia: Trichomycteridae \\ Género: Trichomycterus
}

Tabla 7. Peces de la laguna Aricota

\begin{tabular}{|c|c|c|c|c|c|c|}
\hline $\begin{array}{c}\text { Phyllu } \\
\text { m }\end{array}$ & Clase & Orden & Familia & Género & Especie & $\begin{array}{c}\text { Nombr } \\
\text { e } \\
\text { vulgar }\end{array}$ \\
\hline \multirow{2}{*}{$\begin{array}{c}\text { Chordat } \\
\text { a }\end{array}$} & \multirow{2}{*}{$\begin{array}{l}\text { Actinoptery } \\
\text { gii }\end{array}$} & $\begin{array}{l}\text { Salmoniform } \\
\text { es }\end{array}$ & Salmonidae & $\begin{array}{l}\text { Oncorhymch } \\
\text { us }\end{array}$ & $\begin{array}{l}\text { Oncorhymch } \\
\text { us mykiss }\end{array}$ & Trucha \\
\hline & & Siluriformes & $\begin{array}{l}\text { Trichomycterid } \\
\text { ae }\end{array}$ & $\begin{array}{l}\text { Trichomycter } \\
\text { us }\end{array}$ & $\begin{array}{l}\text { Trichomycter } \\
\text { us sp. }\end{array}$ & Bagre \\
\hline
\end{tabular}

\section{DISCUSIÓN}

La conductividad eléctrica muestra valores altos que oscilan entre 1960-2030 $\mu \mathrm{S} / \mathrm{cm}$, a diferencia de la laguna La Viuda (Lima) con 166-182 $\mu \mathrm{S} / \mathrm{cm}$ (Huanaco et al., 2018), mostrando similitud con otras lagunas altoandinas ubicadas en Pasco, como la laguna Yanamate $(5200 \mu \mathrm{S} / \mathrm{cm})$, laguna Quiulacocha $(3860 \mu \mathrm{S} / \mathrm{cm})$, laguna Milpo Andina (1600 $\mu \mathrm{S} / \mathrm{cm}$ ) (Baylón et al., 2018), lago Titicaca (lago mayor y menor) con 1400-1500 $\mu \mathrm{S} / \mathrm{cm}$ (Dejoux y Iltis, 1991). Según estas mediciones, dichas lagunas (incluida la laguna Aricota) no cumplen con los Estándares Nacionales de Calidad Ambiental (ECA) para el agua: Categoría 4 (Conservación del Ambiente Acuático/Lagos-lagunas) aprobados por D. S. N ${ }^{\circ}$ 004-2017-MINAM (1000 $\mu \mathrm{S} / \mathrm{cm})$, indicando la presencia de contaminantes iones. Moreno (1996) encontró que las proporciones iónicas de los cationes en la laguna Aricota son relativamente uniformes y muestran una relación
$\mathrm{Na}>\mathrm{Ca}>\mathrm{Mg}>\mathrm{K}$; que refleja la presencia de tierras alcalinas y sedimentos calcáreos, porque el río Salado (afluente de la laguna Aricota) tiene concentraciones altas de sales, boro y arsénico (Cutipa, 2014; Escalante, 2016).

Los resultados indican que la laguna Aricota presenta una moderada presencia de comunidades acuáticas (fitoplancton, zooplancton, perifiton, bentos y peces). Esta biota microscópica y macroscópica de los ecosistemas acuáticos lénticos está influenciada por los factores físicos-ambientales; entre ellos los latitudinales, altitudinales, geomorfológicos, precipitación pluvial, gradientes de evapotranspiración y variables fisicoquímicos del agua (oxígeno disuelto, conductividad eléctrica, $\mathrm{pH}$ ). Estos factores en conjunto determinan las condiciones óptimas de hábitat para las poblaciones de la biota acuática.

Los valores resultantes de los parámetros evaluados: temperatura del agua, conductividad 
eléctrica, oxígeno disuelto y $\mathrm{pH}$ de los 5 puntos de muestreo presentan semejanza con lo reportado por los informes técnicos del Programa de Conservación de la Diversidad Biológica realizado por EGESUR (2015).

Respecto al fitoplancton, en el estudio se reportan 52 morfoespecies distribuidas en: 6 Phyllum, 26 ordenes y 31 familias; resultados que concuerdan con lo publicado por Merchan y Sparer (2015). Quienes trabajaron en la variación temporal de fitoplancton de seis lagunas altoandinas en Cuenca-Ecuador, encontrando en cuatro meses de estudio un registro de 79 individuos de fitoplancton, los cuales se distribuyen en 70 familias, 36 ordenes, 14 clases y 8 filos. El grupo con mayor riqueza de morfotipos correspondió a la clase Conjugatophyceae, seguida de Chlorophyceae, Bacillariophyceae y Cyanophyceae, Los cambios en la riqueza de especies no muestran un patrón definido en todas las lagunas a lo largo del tiempo. Esto podría deberse a los cambios específicos que sufre la comunidad de fitoplancton en cada laguna (Melack, 1979).

En lo relacionado al zooplancton, se encontraron 13 morfoespecies distribuidas en: 6 Phyllum, 8 ordenes y 11 familias. Resultados que difieren mucho de lo señalado por Iannacone y Alvariño (2006), reportando en la Reserva Nacional de Junín un total de 35 morfotaxas; donde los artrópoda fueron los más numerosos (22), seguidos por los rotíferos con ocho especies; y, con una especie cada una, los filas Rhizopoda, Cnidaria, Nematoda, Tardigrada y Annelida. Está marcada diferencia de riqueza de especies entre las lagunas Aricota y Junín puede deberse a las diferentes condiciones fisicoquímicas del agua en ambos lugares. En la laguna Aricota, por ejemplo, el pH del agua es muy alcalino; mientras que, en la laguna Junín es de tendencia neutra. Según Valdivia y Burger (1990), el estudio de las comunidades zooplanctónicas presentes en los ecosistemas altoandinos, es importante desde el punto de vista zoogeográfico y ecológico.

Para las comunidades del perifiton, se encontraron 56 morfoespecies distribuidas en: 8
Phyllum, 25 ordenes y 34 familias. Sierra y Ramírez (2000) realizaron la caracterización del ficoperifiton que coloniza sustratos artificiales en el embalse de La Fe-Antioquia. En dicho estudio, se reportó baja biomasa algal perifítica debido al bombeo de agua al embalse, lo que generó una baja presencia de organismos, por lo que el ensamblaje perifítico se mantuvo siempre en la fase inicial de colonización por bacterias. Este último resultado concuerda con la cantidad de perifiton de la laguna Aricota por presentar el mismo caso de extracción de agua por bombeo.

En lo correspondiente a macroinvertebrados, se encontraron 24 especies distribuidas en: 5 Phyllum, 9 ordenes y 16 familias. Estos resultados concuerdan con lo reportado por Baylón, et al. (2018). Quienes evaluaron invertebrados bentónicos como bioindicadores de calidad de agua en lagunas altoandinas de Lima-Perú, identificando un total de cuatro Phylum, 10 clases, 17 ordenes y 34 familias. Siendo el Phylum Arthropoda con mayor riqueza y abundancia de organismos, seguidos del Phylum Annelida y Mollusca. En la mayoría de muestreos, la comunidad de invertebrados bentónicos estuvo representada por la clase Insecta, con 18 familias y 5 ordenes; dentro de los cuales, el orden Díptera fue la más representativa con 7 familias, seguidas del orden coleóptera con 5 familias. Asimismo, Gallozo y Yauri (2017) trabajaron con macroinvertebrados acuáticos como bioindicadores de la calidad del agua, relacionados con metales pesados en la sub cuenca Yanayacu - Ancash, reportando que la comunidad de macroinvertebrados acuáticos muestreados (periodo de avenidas) está representado por los Phylum: Arthropoda, Mollusca, y Annelida; registrándose la presencia de 25 familias en total, con un subtotal de 21 familias en las clases Insecta, un subtotal de 01 familia en la clase Malacostraca, un subtotal de 02 familias en la clase Gastrópoda y un subtotal de 01 familia en la clase Oligochaeta. Se puede observar que la mayor abundancia de familias corresponde al Phylum Arthropoda y dentro de esta a la clase Insecta. 
Es frecuente observa que el Phylum Arthropoda y el orden díptera presentan los mayores valores de riqueza, por lo que resaltan como los más representativos en ecosistemas dulceacuícolas. Las familias características en ecosistemas de este tipo son: Chironomidae, Cyprididae, Corixidae y Hyalellidae; las que suelen aportar con el mayor número de organismos. Dentro del orden Díptera, destaca la familia Chironomidae que se registra frecuentemente en todas las lagunas. En la subfamilia Chironominae se han identificado las especies Chironomus tentas, Chironomus sp. La presencia y dominancia de la familia Chironomidae se debe a sus múltiples estrategias de alimentación (Merrit et al., 2008), por estar adaptado a diferentes factores ambientales o de stress (Domínguez y Fernández, 2009); lo que le ha permitido ser considerado como indicador de contaminación por materia orgánica (Roldán, 1996).

En lo relacionado a la ictiofauna, en el presente trabajo se reportan dos especies que son: Oncorhynchus mykiss (trucha), siendo un organismo introducido y Trichomycterus spp, endémico de la zona. Según Chocano (2005), investigadora del Departamentos de Ictiología y Limnología de la Universidad San Marcos de Lima, la ictiofauna de los Andes es considerada como de escasa diversidad taxonómica, es decir, posee un número reducido de especies, siendo tan solo tres los géneros descritos, los ciprinodóntidos, Orestias y los bagres (Astroblepus y Trichomycterus), conocidos para las zonas del Altiplano y de las mesetas altoandinas.

Sin embargo, en el estudio Riqueza y abundancia de peces en dos lagunas de los Andes tropicales de Bolivia, Miranda-Chumacero y Barrera (2005) reportan para la laguna Chalalán 17 especies agrupadas en nueve familias y tres ordenes, siendo la familia Characidae la que presenta mayor cantidad de especies, seguida por las familias Cichlidae y Loricariidae con dos especies cada una; mientras que en la laguna Santa Rosa, se identificaron también 17 especies agrupadas en nueve familias y cinco ordenes. La familia Characidae fue la que mayor número de especies presentó, seguida por la familia Cichlidae. Según Ortega et al. (2011), en su publicación Lista anotada de los peces de aguas continentales del Perú, se considera que en los altos andes han sido registradas 80 especies sobre los 1000 m s. n. m. (Ortega, 1992), donde 50 de estas especies de aguas frías son endémicas y pertenecen mayormente a los géneros Orestias, Astroblepus y Trichomycterus.

\section{CONCLUSIONES}

Los parámetros monitoreados no presentan grandes variaciones en el caso de temperatura y oxígeno disuelto; pero, sí son inversamente proporcionales. El $\mathrm{pH}$ muestra una condición alcalina en la laguna llegando a valores de 9.03, mostrando diferencia en la zona pelágica y litoral, ya que en la zona pelágica se mantuvo constante a diferencia de la zona litoral con $\mathrm{pH}$ bajo. La conductividad eléctrica es alta respecto a otros cuerpos de agua (ríos, bofedales), con valores alrededor de $300 \mu \mathrm{S} / \mathrm{cm}$; y no tiene una variación significativa con respecto a los meses monitoreados, llegándose a pensar que es una condición típica de ese ecosistema por parte de la condición del río Salado.

Las comunidades acuáticas de la laguna Aricota están conformadas por cinco grandes grupos: Fitoplancton con 52 especies, con una dominancia absoluta de las Bacillariophyta (diatomeas). El perifiton está representado por 56 morfoespecies compuesto por dos subgrupos: cinco grupos de fitoperifiton y cuatro de zooperifiton. Respecto al zooplancton, está representado por 13 morfoespecies, sobresaliendo los Amoebozoa y Arthopoda. Los Macroinvertebrados conformados por 24 morfoespecies, destacando los Arthropoda con la clase Insecta y orden Trichoptera; y lo correspondiente a la Ictiofauna, esta se encuentra compuesto por solo dos especies: Oncorhynchus mykiss como organismo introducido y Trichomycterus $s p$. como especie endémica.

\section{AGRADECIMIENTO}

Se expresa el agradecimiento a la Universidad Nacional Jorge Basadre Grohmann, por el financiamiento canon para la tesis de pregrado "Comunidades acuáticas y redes tróficas de la laguna Aricota y su importancia en el desarrollo acuícola" 


\section{REFERENCIAS}

Alba-Tercedor, J. (1996). Macroinvertebrados acuáticos y calidad de las aguas de los ríos. IV Simposio del agua en Andalucía (SIAGA). Universidad de Granada. Vol. II: P203-213.

Alba-Tercedor, J., Pardo, I., Prat, N. y Pujante, A. (2005). Protocolos de Muestreo y Análisis para Invertebrados Bentónicos. España: Confederación Hidrográfica del Ebro - Ministerio del Medio Ambiente.

Angermeir, P. L., Schlosser, I. J. (1995). Conserving aquatic biodiversity: beyond species and populations. American Fisheries Society Symposium 17, p402414. APHA, AWWA, WEF. (2012). Standard Methods for The Examination and Wastewater. 22 ed. Washington D. C., U.S.A.: American Public Health Association.

Autoridad Nacional del Agua, ANA. (2012). Informe del tercer monitoreo participativo de la calidad de agua superficial del año 2012 en las cuencas Locumba y Sama. 181

Autoridad Nacional del Agua, ANA. (2016). Estudio de los recursos hídricos superficiales y subterráneos e infraestructura hidráulica para el plan de aprovechamiento en la cuenca del río Locumba, en la región de Tacna. Volumen IV. Estudio Hidrológico de la Cuenca del río Locumba. 2094.

Baylón, M., Roa, K., Libio, T., Tapia, L., Jara, E., Macedo, D., Salvatierra, A. Y Dextre, A. (2018). Evaluación de la diversidad de algas fitoplanctónicas como indicadores de la calidad del agua en lagunas altoandinas del departamento de Pasco (Perú). Ecología aplicada, 17(1), 119132.

Bellinger, E. y Sigee, D (2010). Freshwater Algae: Identification and Use as Bioindicators. Wiley-Blackwell, Chichester, West Sussex, UK. 284 pp., ISBN: 978-0-470-05814-5.

Blomqvist, P., (2001). A proposed standard method for composite sampling of water chemistry and plankton in small lakes. Environmental and Ecological Statistics, vol. 8, 121-134.

Boulton, A.J., (1999). An overview of river health assessment: philosophies, practice, problems and prognosis", Freshwater Biology, 41, 469-479.
Branco, S. M. (1978). Hidrobiologia Aplicada a Engenharia Sanitaria. Sao Paulo: CETESB.

Burgess, W. E. (1993). An Atlas of Freshwater and Marine Catfishes: A Preliminary Survey of the Siluriformes (First). Washington D.C., USA: TFH Publishers. 748.

Cambra, J., Ector, L. y Sabater, S., (2005). Protocolos de Muestreo y Análisis para Fitobentos. S.1.: Confederación Hidrográfica del Ebro - Ministerio del Medio Ambiente (España).

Chocano, L. (2005). Las zonas altoandinas peruanas y su ictiofauna endémica. Revista Digital Universitaria, 6(8).

Cowx, I. G., Collares-Pereira, M. J. (2002). Freshwater fish conservation: options for the future. En: Conservation of freshwater fishes: options for the future. 443-452. Oxford: Blackwell Science.

Cutipa, C. V. (2014). Análisis del cambio climático y sus efectos en el comportamiento hidrológico de la laguna Aricota, usando el modelo Weap (tesis Pregrado). Universidad Nacional Jorge Basadre Grohmann. Tacna.

Dejoux, CL. y Iltis, A. (1991). El Lago TiticacaSíntesis del conocimiento limnológico actual. La Paz-Bolivia.

Domínguez, E. y Fernández, H.R., (2009). Macroinvertebrados Bentónicos Sudamericanos. Sistemática y Biología. San Miguel de Tucumán: Fundación Miguel Lillo.

Empresa de Generación Eléctrica del Sur, EGESUR. (2015) 2do informe trimestral de monitoreo ambiental 2015 de las CC. HH. Aricota 1 y 2.

Empresa de Generación Eléctrica del Sur, EGESUR . ( 2017 a). Plan de contingencias operativo CC.HH. Aricota 2017-2018. Perú. 71p.

Empresa de Generación Eléctrica del Sur, EGESUR (2017b). Memoria institucional. Perú. 105p.

Escalante, V. M. (2016). Simulación hidrológica de la laguna Aricota y optimización de la Central Hidroeléctrica Aricota III (Tesis de pregrado). Universidad Nacional Agraria La Molina. Lima.

Ferrario, M.E., Sar, E. y Sala, S. (1995). Metodología básica para el estudio del fitoplancton con especial referencia a las diatomeas. En: Alveal K., M.E. Ferrario, E. C. Oliveira y E. Sar (Eds.) Manual de 
Métodos Ficológicos. Capítulo Universidad de Concepción.

Figueroa, R., Soria, M., Beltran, M. y Correa, F. (2016). Estudio de comunidades biológicas como bioindicadores de calidad de agua. Seminario Internacional Estudio de comunidades biológicas como bioindicadores de calidad de agua. 26-34.

Ga11ozo, A. y Yauri J. ( (2017). Macroinvertebrados acuáticos como bioindicadores de la calidad del agua, relacionados con metales pesados en la sub cuenca Yanayacu - Ancash, setiembre 2015 - abril 2016. Universidad Nacional "Santiago Antúnez De Mayolo".

Hartley, B., Barber, H.G., Carter, J.R. Y Sims, P.A. (1996). An atlas of British diatoms. Bristol: Biopress Ltd.

Hillebrand, H., Frost, P. y Liess, A. (2008). Ecological stoichiometry of indirect grazer effects on periphyton nutrient content. Oecologia, 155, 619-630.

Huanaco, J., Montoya, H., Castellanos, P. y Quiroz, A. (2018). Evaluación de la diversidad del fitoplancton de la laguna La Viuda (Lima, Perú) en agostonoviembre 2016. Arnaldoa, 25 (3), p1027-1040.

Iannacone, J. y Alavariño, L. (2006). Diversidad del Zooplancton en la Reserva Nacional de Junín, Perú. Ecología Aplicada, 5 $(1,2), 175-181$.

Jairo, J. (2000). Fitoplancton de agua dulce. Colombia: Universidad de Antioquia.

Kotov, A. A. y Ŝtifter, P. (2006). Cladocera: family Ilycryptidae (Branchiopoda: Cladocera: Anomopoda). Guides to the identification of the Microinvertebrates of the continental Waters of the World. $\mathrm{N}^{\circ}$ 22. Bélgica: Backhuys Publishers $\mathrm{y}$ Kenobi Production

Lange-Bertalot, H., Moser, G. y Metzeltin, D. (1998). Insel der Endemiten. Geobotanisches Phänomen Neukaledonien. Island of endemics New Caledonia - a geobotanical phenomenon. Bibliotheca Diatomologica 38: [1]-464, 101.

Likens, W. (2010). Lake Ecosystem Ecology. Millbrook: Elsevier Academic Press.

Margalef, L. R. (1983). Limnología. Barcelona: Omega.

Market, B.A., Breure, A. M. y Zechmeister, H. G. (2003). Bioindicators \& Biomonitors.
Principles, Concepts and Applications. Amsterdan, Boston: Elsevier.

McAlice, B. J. (1971), Phytoplankton sampling with the Sedgewick- Rafter-Cell, Limnology and Oceanography, 16, doi: 10.4319/lo.1971.16.1.0019.

Melack, J. (1979). Temporal Variability of Phytoplankton in Tropical Lakes. Oecologia, 44(1), 1-7.

Merchán, D. y Sparer, A. (2015). Variación temporal de fitoplancton de seis lagunas altoandinas en relación a las características físico-químicas del medio. S.l.: Universidad de Cuenca.

Merritt, R.W., Cummins, K.W. y Berg, M.B. (2008). An Introduction to the Aquatic Insects of North America. Cuarta. S.1.: Kendall/Hunt.

Miranda-Chumacero, G. y Barrera, S. (2015). Riqueza y abundancia de peces en dos lagunas de los Andes tropicales. Ecología en Bolivia, 40(2), 41-52.

Morán, E. (2018). Diversidad ictiológica de las principales cuencas hidrográficas del departamento de Tacna (Tesis de pregrado). Universidad Nacional Jorge Basadre Grohmann. Tacna.

Moreno, L. (1996). Lagunas altoandinas del sur del peru: Caracteristicas químicas, Revista Ciencia \& Desarrollo, Universidad Nacional Jorge Basadre Grohmann, Tacna.

Moss, B. (2010). Ecology of Freshwater: a view for the twenty-first century. Fourth Edition. University of Liverpool: WileyBlackwell.

Oberdorff, T., Pont, D., Hugueny, B., Porcher, J.P. (2002). Development and validation of a fish-based index for the assessment of 'river health' in France. Freshwater Biology, 47, 1720-1734.

Ortega, H. (1992). Biogeografía de los Peces de Aguas Continentales del Perú, con especial referencia a especies registradas a altitudes superiores a los 1000 metros. Memorias del Museo de Historia Natural, UNMSM, 21, 39-45.

Ortega, H., Hidalgo, M., Correa, E., Espino, J., Chocano, L., Trevejo, G., Meza, V., Cortijo, A.M. y Quispe, R. (2011). Lista anotada de los peces de aguas continentales del Perú: Estado actual del conocimiento, distribución, usos y aspectos de conservación. Lima: Ministerio del Ambiente, Dirección General de Diversidad Biológica - 
Museo de Historia Natural, UNMSM.

O'Sullivan, P. E. y Reynolds, C. S. (2004). The Lakes Handbook. Vol. 1. Limnology and Limnetic Ecology. USA: Blackwell Publishing.

Pavé, P. y Marchese, M. (2005). Invertebrados bentónicos como indicadores de calidad del agua en ríos urbanos (Paraná-Entre Ríos, Argentina). Ecología Austral, 15, 183-197.

Prat, N., Acosta, R., Villamarín, C. y Rieradevall, M. (2011). Guía para el reconocimiento de las larvas de Chironomidae (Diptera) de los ríos altoandinos de Ecuador y Perú. España: Universidad de Barcelona.

Roldán, P. G. (1992). Fundamentos de Limnología Neotroropical. Medellín: Universidad de Antioquia.

Roldán, G. (1996). Guía para el estudio de los macroinvertebrados acuáticos del Departamento de Antióquia. Medellín: Colciencia / Fen Colombia/ Universidad de Antioquia.

Roldán, P. G. y Ramírez, R. J. (2008). Fundamentos de limnología neotropical. 2da Edición. Medellín: Universidad de Antioquia.

Round, F.E., Crawford, R.M. y Mann, D.G. (1990). The Diatoms. Biology and Morphology of the Genera. Cambridge University Press, Cambridge, 747.

Ruiz-Moreno, J. L., Ospina-Torres, R., GómezSierra, H. y Riss, W. (2000). Guía para la identificación genérica de larvas de quironómidos (diptera: chironomidae) de la sabana de Bogotá. III. Subfamillas Tanypodinae, Podonominae y Diamesinae. Caldasia, 22(1), 34-60.

Schwoerbel, L. (1966). Methods of Hydrobiology (Freshwater Biology). Pergamon Press.

Segers, H. (1995). Zoogeography of litoral Rotifera, with special reference to the Lecanidae. Part II: Morphology and taxonomy of Lecane. Bélgica: SPB Academic Publishing

Serfling, R. E. (1949). Quantitative estimation of plankton from small samples of Sedgewick- Rafter-Cell mounts of concentrate samples. Transactions of the American Microscopical Society, 68(3), 185-199.

Sierra, O. y J. Ramírez. (2000). Variación espacio - temporal de biopelículas en la represa $\mathrm{La} \mathrm{Fe}$, el Retiro, Antioquia (Colombia).
Actualidades Biológicas, 22(73), 153168.

Smirnov, N. N. (1992). The Macrothricidae of the World. Guides to the identification of the Microinvertebrates of the continental Waters of the World. $\mathrm{N}^{\circ} 1$. Bélgica: SPB Academic Publishing.

Smirnov, N. N. (1996). Cladocera: The Chydorinae and Sayciinae (Chydoridae) of the World. Guides to the identification of the Microinvertebrates of the continental Waters of the World. $\mathrm{N}^{\circ} 11$. Bélgica: SPB Academic Publishing.

Sostoa, A., García De Jalón, D., y GarciaBerthou, E. (2005). Protocolos de muestreo y análisis para ictiofauna, $\mathrm{p}$. 179-213. En De La Fuente, M. J. (Ed.), Metodología para el establecimiento del estado ecológico según la directiva marco del agua en la Confederación hidrográfica del Ebro. España: Ministerio del Medio Ambiente.

Stevenson, R. J., Bothwell, M. L. y Lowe, R. L. (1996). Algal ecology freshwater benthic ecosystems. San Diego: Academic Press.

Stevenson, R.J. y Rollins, S.L. (2007). Ecological Assessments with Benthic Algae. En: F.R. HAUER y G.A. LAMBERTI (eds.), Methods in Stream Ecology. S.1.: Elsevier Academic Press.

Streble, H. y Krauter, D. (1987) Atlas de los microorganismos de agua dulce, la vida en una gota de agua. Editorial Omega. 125p. ISBN: 84-282-0800-X

Valdivia R. y Burger L. (1990). Observaciones sobre la fauna Cladócera de algunas lagunas Alto andinas del Perú. Boletín de Lima, 71, 63-79.

Vicente, E., De Hoyos, C., Sánchez, P. y Cambra, J. (2005). Protocolos de Muestreo y Análisis para Fitoplancton. España: Confederación Hidrográfica del Ebro Ministerio del Medio Ambiente.

Villafane, V. y Reid, F. (1995) Métodos de microscopia para la cuantificación del fitoplancton. En: Alveal, K., Ferreiro, M.E., Oliviera, E.C. and Ferreiro, M.A., Eds., Manual de Métodos Ficológicos, Universidad de Concepción, Concepción, 169-185.

Wichert, G.A., Rapport, D.J. (1998) Fish community structure as a measure of degradation and rehabilitation of riparian systems in an agricultural drainage basin. Environmental Management, 22,425-443. 